\title{
Egg consumption and cardiovascular disease events - evidence from the Caerphilly prospective cohort study
}

Eggs are regarded as an economic and nutrient dense food, but they are also rich in cholesterol ${ }^{(1)}$. Limiting egg consumption is recommended as a strategy for LDL-cholesterol reduction, a key risk factor for cardiovascular disease (CVD). However, recent evidence suggests the effect of cholesterol in eggs to be negligible when compared with the impact of dietary saturated fatty $\operatorname{acids}^{(2)}$. A limited number of studies have investigated the effects of egg consumption on CVD using prospective cohort data, with inconsistent results. The present study investigated the prospective relationship between egg consumption and incidence of stroke, myocardial infarction (MI), heart failure (HF), and (any cause) mortality as well as cross-sectional relationships between egg consumption and metabolic risk markers using data from the Caerphilly Prospective Cohort Study.

Included in this cohort were 2,512 men, aged 45-59 years at baseline, who were followed up at 5 years intervals for a mean of 22.8 years. With adjustments for dietary and lifestyle variables, Cox regression and multiple linear regression analysis were used to examine the longitudinal and cross-sectional relationships, respectively. Furthermore, because earlier studies suggest that higher egg consumption will increase the risk of heart disease in diabetics but not in healthy individuals ${ }^{(3)}$, separate analyses were completed using data from i) healthy men and ii) men with impaired glucose tolerance (IGT) and diagnosed diabetes (DM) at baseline.

\begin{tabular}{|c|c|c|c|c|c|c|c|c|}
\hline \multirow{3}{*}{$\begin{array}{l}\text { Egg intake } \\
\text { (number/week) }\end{array}$} & \multicolumn{8}{|c|}{ Stroke (adjusted) } \\
\hline & \multicolumn{2}{|c|}{ Healthy $(n=2036)$} & \multicolumn{2}{|c|}{ DM \& IGT $(n=279)$} & \multicolumn{2}{|c|}{$\mathrm{DM}(\mathrm{n}=72)$} & \multicolumn{2}{|c|}{$\operatorname{IGT}(\mathrm{n}=254)$} \\
\hline & $\overline{\mathrm{HR}}$ & $\mathrm{SE}$ & $\overline{\mathrm{HR}}$ & $\mathrm{SE}$ & $\overline{\mathrm{HR}}$ & $\mathrm{SE}$ & $\overline{\mathrm{HR}}$ & SE \\
\hline $0-1$ & 1.00 & & $1 \cdot 00$ & & $1 \cdot 00$ & & 1.00 & \\
\hline 2 & 1.00 & $0 \cdot 19$ & 0.54 & $0 \cdot 27$ & $0 \cdot 13$ & $0 \cdot 15$ & 0.68 & $0 \cdot 38$ \\
\hline 3 & 1.03 & $0 \cdot 21$ & $0 \cdot 83$ & 0.41 & 1.20 & $1 \cdot 15$ & 1.03 & 0.58 \\
\hline $4-5$ & $1 \cdot 13$ & 0.23 & 1.47 & 0.64 & 1.72 & 1.58 & 1.81 & 0.91 \\
\hline $6-40$ & 1.40 & $0 \cdot 30$ & 1.71 & 0.78 & $0 \cdot 32$ & $0 \cdot 38$ & $2 \cdot 36$ & $1 \cdot 23$ \\
\hline $\mathrm{P}$ for trend & $0 \cdot 100$ & & 0.028 & & 0.729 & & 0.009 & \\
\hline
\end{tabular}

The findings from the longitudinal analysis suggest that weekly consumption of up to six eggs is unlikely to have a substantial impact on the risk of CVD or mortality (all cause) among healthy men ( $\mathrm{P}$ for trend $=0 \cdot 100)$. However, increased risk of stroke was associated with higher egg consumption among participants with IGT or suffering from diabetes $(\mathrm{P}$ for trend $=0.028)$. However, the cross-sectional analysis did not find any significant effect of higher egg consumption on the concentration of total cholesterol, HDL-cholesterol, LDL-cholesterol, triacylglycerol and insulin in venous blood from fasted subjects. Similarly there was no effect of egg consumption on systolic and diastolic blood pressure. The cross-sectional analysis did however indicate that consumption of up to six eggs per week may elevate fasting glucose concentration in subjects who had DM and IGT $(\mathrm{P}$ for trend $=0.017)$, but this was not found in the healthy population $(\mathrm{P}$ for trend $=0.664)$. Clearly the interaction between egg consumption and diabetes (DM and IGT) needs detailed study.

1. Benelam B, Roe M, Pinchen H et al. (2012) Nutr Bull 37, 344-349.

2. Gray J \& Griffin B (2009) Nutr Bull 34, 66-70.

3. Hu FB, Stampfer MJ, Rimm EB et al. (1999) JAMA 281, 1387-1394. 